\title{
O PERFIL DO PROFESSOR BRASILEIRO DE SOCIOLOGIA DO ENSINO MÉDIO E SUA PERCEPÇÃO DA CONDIÇÃO DOCENTE
}

\author{
Cristiano das Neves Bodart ${ }^{1}$ \\ Roniel Sampaio Silva ${ }^{2}$
}

\section{RESUMO}

Este paper busca apresentar parte de uma pesquisa predominantemente quantitativa aplicada a 550 professores de Sociologia de todas as Regiões brasileiras, que responderam um questionário online presente em um blog de Sociologia. Juntamente com essa coleta de dados, recorremos a fontes do Censo Escolar INEP (de 2007 a 2012). O objetivo é apresentar elementos que venham a colaborar na busca pela compreensão do perfil do professor de Sociologia de Ensino Médio, assim como identificar elementos que nos possibilitem evidenciar suas condições de prática docente a partir de sua percepções. Dentre os resultados, destacamos as dificuldades no uso de recursos didáticos, a desvalorização da disciplina e a falta de professores licenciados em Ciências Sociais/Sociologia. Acreditamos que a presente pesquisa pode contribuir para repensarmos as políticas educacionais ligadas à docência em Sociologia.

Palavras-chave: Ensino de Sociologia. Perfil do Professor. Condição da Prática Docente.

\section{ABSTRACT}

This paper aims to present a part of a predominantly quantitative research applied to 550 Sociology teachers from all Brazilian regions. They answered the online questionnaire in a blog on Sociology. Along with this collection of data, we made use of the sources from the INEP School Census (2007-2012). The goal is to present information that may corroborate the search for understanding the profile of the secondary education sociology professor, thereby identifying elements that may enable us to identify the teaching conditions from his perception. Among the results, we highlight the difficulties in the use of instructional resources, the devaluation of the discipline, and lack of teachers licensed in Social Sciences / Sociology. We believe this present research contributes to a rethinking of educational policies related to teaching in Sociology.

\footnotetext{
${ }^{1}$ Graduado em Ciências Sociais, doutor em Sociologia pela Universidade de São Paulo (USP). Email: cristianobodart@hotmail.com

${ }^{2}$ Graduado em Ciências Sociais pela UFPI e mestre em Educação pela Universidade Estadual de Rondônia (UNIR). E-mail: ronielsampaio@hmail.com
} 
O PERFIL DO PROFESSOR BRASILEIRO DE SOCIOLOGIA DO ENSINO MÉDIO E SUA

PERCEPÇÃO DA CONDIÇÃO DOCENTE

Cristiano das Neves Bodart

Roniel Sampaio Silva

Keywords: Teaching Sociology. Teacher Profile. Condition of Teaching.

\section{INTRODUÇÃO E PROCEDIMENTOS METODOLÓGICOS}

Ainda que o objetivo deste paper não seja realizar um balanço histórico do lugar da Sociologia no Ensino Médio, parece-nos bastante frutífero apresentar um breve esboço desse histórico para compreendermos as dificuldades já enfrentadas pelos docentes dessa disciplina.

A Sociologia passou a compor a grade curricular da escola secundária ${ }^{3}$ em 1925, com a Reforma Rocha Vaz. A partir da Lei Francisco Campos, n. 19.890, de 1931, essa disciplina manteve-se obrigatória até 1942 nos cursos preparatórios para os Institutos de Ensino Superior.

Art. 4ㅇ $\mathrm{O}$ curso complementar, obrigatório para os candidatos à matrícula em determinados institutos de ensino superior, será feito em dois anos de estudo intensivo, com exercícios e trabalhos práticos individuais, e compreenderá as seguintes matérias: [...] Sociologia [...] (Decreto n. 19.890, de 1931).

Para Nascimento (2010), a Sociologia encaixava-se no espírito da época: modernização brasileira via urbanização. A esse respeito, Meucci (2000, p. 2) afirma que

[...] entre os anos de 1931 e 1945 cerca de duas dezenas de livros didáticos de sociologia foram publicados no Brasil. Eram, pois, livros introdutórios, compêndios, tratados, dicionários, coletâneas de textos e periódicos destinados ao ensino secundário regular, aos cursos de magistério, faculdades e universidades. Trata-se de um conjunto significativo de obras, revelador do estabelecimento de um sistema de difusão do conhecimento sociológico.

Parece-nos claro que na década de 1930 houve um esforço considerável para firmar a Sociologia como uma disciplina no ensino preparatório para o ensino

\footnotetext{
${ }^{3}$ Para maior aprofundamento da História de inclusão e exclusão da Sociologia no Ensino Básico brasileiro, ver Moraes (2011).
}

Inter-legere - Revista de Pós-Graduação em Ciências Sociais da UFRN Natal RN, ISSN 19821662 no 18 jan./jun de 2016 p. 168-189 
O PERFIL DO PROFESSOR BRASILEIRO DE SOCIOLOGIA DO ENSINO MÉDIO E SUA

PERCEPÇÃO DA CONDIÇÃO DOCENTE

Cristiano das Neves Bodart

Roniel Sampaio Silva

superior. Nesse período, ela passou a ser difundida em setores mais amplos da classe média, via ensino secundário, e, por extensão, chegou, mediante movimentos políticos contestatórios, às camadas trabalhadoras engajadas no movimento sindical e partidário. Contudo, foi retirando oficialmente sua obrigatoriedade em 1942, por meio da Reforma Capanema ${ }^{4}$.

Os posteriores passos da Sociologia no ensino secundário foram instáveis, sendo excluída e incluída por diversas vezes nesse nível de ensino. Em 1961, a Lei de Diretrizes e Bases da Educação (LDB), n. 4.024, retornou com a obrigatoriedade da Sociologia no ensino secundário. Em 1971, por meio da LDB, n. 5.692, essa disciplina passou a ser optativa, juntamente com outras 104 . Nos parece que o modelo de educação tecnicista da década de 1970 não deixou espaço para a Sociologia. Em 1982, a Lei de n. 7.044 reabriu espaços para as disciplinas de Ciências Humanas. Iniciaram-se, então, movimentos em vários estados da federação que lutaram pelo retorno dessa disciplina ao Ensino Médio, fato que somente ocorreu oficialmente ${ }^{5}$ na esfera federal no ano de $2008^{6}$.

O retorno recente da Sociologia ao Ensino Médio brasileiro foi bastante problemático. Se, por um lado, existiam, em 2008, 23.561 escolas de Ensino Médio que implantariam a disciplina no ano seguinte, por outro, a formação de licenciado em Sociologia era bastante deficitária. Os anos de exclusão dessa disciplina induziram muitas universidades, devido à falta de mercado de trabalho, a fecharem os cursos de licenciatura, mantendo apenas o bacharelado. Além disso, havia uma questão importante em debate: quais conteúdos de sociologia ensinar no Ensino Médio? (MORAES, 2011).

Dados do censo de 2007, realizado pelo INEP/MEC (2009), indicam que havia na ocasião 19.776 professores de Sociologia atuando no Ensino Médio. As pesquisas desse mesmo órgão (2012) apontam que existiam em 2012497.797

\footnotetext{
${ }^{4}$ Embora continuasse sendo ministrada nas escolas durante quase todo o período da ditadura Varguista.

${ }^{5}$ Resolução n. 4 de 16 de agosto do CNE, publicada no DOU de 21 de agosto de 2006, Seção 1, página 15.

Seu retorno foi aprovado pelo Conselho Nacional de Educação em 07 de julho de 2006 e homologado em 11 de agosto do mesmo ano. A obrigatoriedade teve início, como indicava o dispositivo jurídico, em 2007.
} 
O PERFIL DO PROFESSOR BRASILEIRO DE SOCIOLOGIA DO ENSINO MÉDIO E SUA PERCEPÇÃO DA CONDIÇÃO DOCENTE

Cristiano das Neves Bodart

Roniel Sampaio Silva

professores de Sociologia na Educação Básica. Considerando esse último dado, essa pesquisa representaria cerca de $0,11 \%$ dos professores de Sociologia de Ensino Médio no país ${ }^{7}$.

Embora exista uma pesquisa realizada pelo INEP/MEC referente ao perfil dos professores, optamos por fazer um estudo paralelo, por acreditarmos que as do INEP podem possuir um problema de aplicação metodológica que vem comprometendo seus resultados. Os questionários produzidos pelo INEP/MEC são encaminhados às escolas e não aos professores, o que propicia condições para que seu preenchimento seja feito por terceiros. Para exemplificar o problema, um dos autores deste artigo, embora tenha lecionado Sociologia no Ensino Médio por cerca de 10 anos, preencheu tais formulários apenas uma única vez, sendo os demais respondidos pela secretária escolar. Durante todo esse tempo como professor de Sociologia, descobriu, no seu décimo ano de docência, que o campo "formação do professor" indicava "licenciado em Geografia", pois lecionava Sociologia e Geografia naquela escola. Por certo esse problema se repete em muitas escolas brasileiras. Por esse motivo, buscamos aplicar o questionário diretamente com professor de Sociologia, a fim de termos, além da pesquisa produzida pelo INEP/MEC, outra que nos auxilie na compreensão do perfil do docente de Sociologia.

O presente trabalho tem por objetivo, após menos de uma década do retorno oficial da Sociologia ao currículo do Ensino Médio, colaborar para a compreensão do perfil do professor de Sociologia do Ensino Médio e suas condições de prática docente. Existem diversos trabalhos que buscam debruçar-se sobre as condições e o perfil do professor de Sociologia, porém, estes limitam-se a um reduzido espaço geográfico, como os estudos desenvolvidos por Lennert (2011), ao estudar a realidade de São Paulo-SP, Sousa e Ribeiro (2012), de Picos-PI, Scheffer (2011), de Juiz de Fora-MG, e Santos (2002), de Brasília-Distrito Federal.

A coleta dos dados foi realizada no primeiro semestre de 2013por meio de questionário hospedado em uma plataforma online, estando estruturado em vinte

\footnotetext{
${ }^{7}$ Embora nosso foco tenha o Ensino Médio, vale lembrar que em alguns municípios a Sociologia também é obrigatória no Ensino Fundamental.
} 
O PERFIL DO PROFESSOR BRASILEIRO DE SOCIOLOGIA DO ENSINO MÉDIO E SUA

PERCEPÇÃO DA CONDIÇÃO DOCENTE

Cristiano das Neves Bodart

Roniel Sampaio Silva

cinco (25) questões fechadas e uma (01) aberta. O questionário foi respondido voluntariamente por 605 professores, sendo 550 atuantes no Ensino Médio de todo o país. Neste artigo, iremos nos deter aos questionários respondidos pelos professores que lecionam Sociologia do Ensino Médio; seja na rede pública, seja na rede privada de ensino. O tratamento dos dados foi feito com o uso do programa IBM SPSS® versão 18.

A divulgação de tal questionário online deu-se pelo "blog Café com Sociologia"8 e pela rede social Facebook, via fanpage do mesmo blog ${ }^{9}$. A adesão aos questionários foi voluntária, não havendo nenhuma retribuição como forma de prêmio ou promessas de sorteio; entretanto, houve ampla divulgação e esclarecimentos sobre o objetivo da pesquisa.

O artigo está dividido em quatro (04) seções. A primeira corresponde à presente introdução. A segunda seção destina-se à apresentação do perfil do(a) professor(a) de Sociologia identificado na pesquisa. A terceira parte tem por objetivo apontar as condições de trabalho dos professores de Sociologia no Ensino Médio a partir de suas próprias perspectivas. Por fim, apresentamos algumas considerações finais.

\section{O PERFIL DO PROFESSOR DE SOCIOLOGIA}

Conhecer o perfil e, principalmente, as condições docentes do professor de Sociologia é uma tarefa árdua, mas necessária. Alguns trabalhos buscaram apontar elementos constitutivos do perfil do professor de Sociologia do Ensino Médio, porém, a dificuldade de coletar dados e o acesso aos professores tornaram esses trabalhos bastante limitados geograficamente. A pesquisa que realizamos não é um censo, nem mesmo uma pesquisa amostral aleatória, a qual apresenta algumas limitações. Trata-se de uma coleta de dados produzida por professores respondentes de um

\footnotetext{
${ }^{8}$ Blog disponível em: <http://www.cafecomsociologia.com/>. O website existe há cerca de cinco anos, tendo hoje aproximadamente 4,5 mil visualizações de páginas diariamente e cerca de 2.700 seguidores via GoogleFriend Connect.

${ }_{9}$ Fanpage disponível em: <https://www.facebook.com/cafecomsociologia>. A página conta hoje com cerca de 70 mil seguidores.
} 
O PERFIL DO PROFESSOR BRASILEIRO DE SOCIOLOGIA DO ENSINO MÉDIO E SUA

PERCEPÇÃO DA CONDIÇÃO DOCENTE

Cristiano das Neves Bodart

Roniel Sampaio Silva

questionário, os quais tiveram, de alguma forma, acesso ao blog Café com Sociologia e desejaram voluntariamente responder as questões propostas.

Apresentando o perfil dos professores que fizeram parte desta pesquisa, notamos a predominância de docentes do sexo feminino (59,1\%). A Tabela 1 aponta a distribuição dos questionados pelas regiões brasileiras. A maioria dos professores respondentes é do Sudeste brasileiro, fato possivelmente provocado pela maior concentração de professores nessa região e pelo maior acesso à internet e, consequentemente, ao questionário nessa localidade.

Buscamos comparar a distribuição por região brasileira de professores de Sociologia que participaram da nossa pesquisa com os identificados pela pesquisa do INEP/MEC, a fim de observar se há disparidades que possam comprometer os resultados que obtivemos.

Tabela 1 - Distribuição, por regiões brasileiras, de professores em geral e de professores de Sociologia

\begin{tabular}{lcr}
\hline Região de atuação & $\begin{array}{c}\text { Presente } \\
\text { pesquisa }\end{array}$ & \multicolumn{2}{c}{ INEP/MEC } \\
\hline Sudeste & 40,5 & 20,4 \\
Nordeste & 22,9 & 24,72 \\
Sul & 18,2 & 14,6 \\
Centro-Oeste & 10,0 & 8,9 \\
Norte & 8,4 & 10,2 \\
\hline Total & $\mathbf{1 0 0}$ & $\mathbf{1 0 0}$
\end{tabular}

Fonte: Elaborada pelos autores com base na pesquisa do INEP/Censo Escolar de 2012 e no presente estudo (2013).

Ao buscarmos nos dados do INEP/MEC a distribuição dos professores nas regiões brasileiras, notamos um problema: $21,18 \%$ dos dados são inválidos, o que compromete o resultado daquela pesquisa. Ao realizarmos a comparação da distribuição de professores pelas regiões brasileiras destacadas pelo INEP/MEC com a distribuição dos respondentes da presente pesquisa, identificamos uma 
O PERFIL DO PROFESSOR BRASILEIRO DE SOCIOLOGIA DO ENSINO MÉDIO E SUA

PERCEPÇÃO DA CONDIÇÃO DOCENTE

Cristiano das Neves Bodart

Roniel Sampaio Silva

proximidade dos resultados. Percebemos uma disparidade mais significativa apenas em relação à região Sudeste. Dessa forma, podemos considerar que a referida pesquisa está proporcionalmente próxima à distribuição dos professores pelas regiões brasileiras, o que acreditamos colaborar na validação dos esforços aqui apreendidos, ainda que com suas limitações. Além disso, a pesquisa objetivou identificar a distribuição geográfica dos respondentes, como se observa na Tabela 2

Tabela 2 - Distribuição dos questionados por estados brasileiros

\begin{tabular}{|c|c|c|}
\hline Estado em que atua & Frequência & $\%$ \\
\hline São Paulo & 110 & 20 \\
\hline Minas Gerais & 57 & 10,4 \\
\hline Paraná & 57 & 10,4 \\
\hline Rio de Janeiro & 42 & 7,6 \\
\hline Ceará & 27 & 4,9 \\
\hline Mato Grosso do Sul & 24 & 4,4 \\
\hline Santa Catarina & 23 & 4,2 \\
\hline Pará & 21 & 3,8 \\
\hline Rio Grande do Sul & 19 & 3,5 \\
\hline Paraíba & 18 & 3,3 \\
\hline Bahia & 17 & 3,1 \\
\hline Alagoas & 16 & 2,9 \\
\hline Espírito Santo & 16 & 2,9 \\
\hline Maranhão & 15 & 2,7 \\
\hline Distrito Federal & 11 & 2,0 \\
\hline Sergipe & 11 & 2,0 \\
\hline Goiás & 9 & 1,6 \\
\hline Mato Grosso & 9 & 1,6 \\
\hline Piauí & 9 & 1,6 \\
\hline Rondônia & 8 & 1,5 \\
\hline Acre & 7 & 1,3 \\
\hline Pernambuco & 7 & 1,3 \\
\hline Rio Grande do Norte & 6 & 1,1 \\
\hline Tocantins & 5 & 0,9 \\
\hline Amazonas & 4 & 0,7 \\
\hline
\end{tabular}


INTER-LEGERE

O PERFIL DO PROFESSOR BRASILEIRO DE SOCIOLOGIA DO ENSINO MÉDIO E SUA

PERCEPÇÃO DA CONDIÇÃO DOCENTE

Cristiano das Neves Bodart

Roniel Sampaio Silva

\begin{tabular}{lrr} 
Amapá & 2 & 0,4 \\
\hline Total & $\mathbf{5 5 0}$ & $\mathbf{1 0 0}$
\end{tabular}

Fonte: Elaborada pelos autores com base nos questionários aplicados em 2013.

Observando a Tabela 2, identificamos que, embora exista um maior número de professores respondentes a essa pesquisa no Sudeste, alguns estados brasileiros de regiões diferentes tiveram significativo volume de professores participantes, tais como Paraná (Sul), Ceará (Nordeste), Mato Grosso do Sul (Centro-Oeste) e Pará (Norte) ${ }^{10}$.

Outra observação realizada diz respeito à distribuição dos professores de Sociologia por rede de ensino. A Tabela 3, abaixo, apresenta os dados coletados.

Tabela 3 - Distribuição dos questionados por rede de atuação

\begin{tabular}{lrr}
\hline Rede de atuação Profissional & Frequência & \% \\
\hline Apenas na Rede Pública & 415 & $\mathbf{7 5 , 5}$ \\
Apenas na Rede Privada & 53 & 9,6 \\
Tanto na Rede Pública como na Rede Privada & 40 & 7,3 \\
Predominantemente na Rede Pública & 32 & 5,8 \\
Predominantemente na Rede Privada & 10 & 1,8 \\
\hline Total & $\mathbf{5 5 0}$ & $\mathbf{1 0 0}$
\end{tabular}

Fonte: Elaborada pelos autores com base nos questionários aplicados em 2013.

A Tabela 3 apresenta a distribuição dos professores de Sociologia do Ensino Médio de acordo com a rede de ensino em que atuam. Como já era esperado, percebemos que maior parte deles atua na Rede Pública de Ensino. Quanto aos professores da Rede Privada, consistem em apenas 9,6\%, embora possam chegar a $25 \%$, se considerarmos os que também estão na Rede Pública. Os dados do censo INEP/MEC (2012) indicam que $87,4 \%$ dos professores de Sociologia do Ensino Médio trabalham na Rede Pública. Em nosso levantamento, esse percentual é de $88,4 \%$.

\footnotetext{
${ }^{10}$ Apenas no estado de Roraima não houve professor de Sociologia que respondesse o questionário.
} 
O PERFIL DO PROFESSOR BRASILEIRO DE SOCIOLOGIA DO ENSINO MÉDIO E SUA PERCEPÇÃO DA CONDIÇÃO DOCENTE

Cristiano das Neves Bodart

Roniel Sampaio Silva

A pesquisa constatou que $76,7 \%$ dos professores respondentes ensinam exclusivamente no Ensino Básico, o que pode ser explicado pelo fato de a disciplina não ser obrigatória no Ensino Fundamental.

$\mathrm{Na}$ Tabela 4, destacamos a distribuição dos professores de Sociologia respondentes desta pesquisa de acordo com sua formação.

Tabela 4 - Distribuição dos questionados por formação.

\begin{tabular}{lrr}
\hline Formação superior & Frequência & $\%$ \\
\hline Licenciado em Ciências Sociais/Sociologia & 188 & 34,2 \\
Licenciado e Bacharel em Ciênc. Sociais/Sociologia & 149 & 27,1 \\
Licenciado em Pedagogia & 35 & 6,4 \\
Graduando em Ciências Sociais/Sociologia & 33 & 6 \\
Licenciado em História & 32 & 5,8 \\
Bacharel em Ciências Sociais/Sociologia & 31 & 5,6 \\
Outra formação & 30 & 5,5 \\
Licenciado em Filosofia & 15 & 2,7 \\
Licenciado em Geografia & 11 & 2 \\
Graduando em Pedagogia & 10 & 1,8 \\
Graduando em História & 6 & 1,1 \\
Licenciado e Bacharel em Filosofia & 4 & 0,7 \\
Bacharel em área de Ciências Exatas/Naturais & 2 & 0,4 \\
Licenciado na área de Ciências Exatas/Naturais & 2 & 0,4 \\
Bacharel em Filosofia & 1 & 0,2 \\
Bacharel em Geografia & 1 & 0,2 \\
\hline Total & $\mathbf{5 5 0}$ & $\mathbf{1 0 0}$
\end{tabular}

Fonte: Elaborada pelos autores com base nos questionários aplicados em 2013.

Com relação à formação, e analisando os dados de maneira transversal, a Tabela 4 mostra que $61,3 \%$ dos respondentes eram licenciados em Ciências Sociais/Sociologia.

O Censo dos Profissionais da Educação de 2012 aponta que 19,42\% dos professores de Sociologia possuíam licenciatura em Ciências Sociais/Sociologia, resultado bem diferente do que encontramos nessa pesquisa (INEP/MEC, 2009). 
O PERFIL DO PROFESSOR BRASILEIRO DE SOCIOLOGIA DO ENSINO MÉDIO E SUA PERCEPÇÃO DA CONDIÇÃO DOCENTE

Cristiano das Neves Bodart

Roniel Sampaio Silva

Para uma possível explicação dessa disparidade, apontamos duas hipóteses: i) como o questionário estava hospedado em um blog voltado prioritariamente para professores de Sociologia, pode ser que tenha havido um interesse maior dentre os licenciados por buscar na internet assuntos ligados à Sociologia; ii) como o INEP encaminha o questionário para as escolas e não para o professor, em muitos casos tais questionários são preenchidos pela secretária da escola, o que pode comprometer os resultados, como já mencionado. Observamos, por meio da Tabela 4, que o percentual de pedagogos e graduados em História é bastante significativo, sendo $6,4 \%$ e $5,8 \%$, respectivamente. Identificar que $38,7 \%$ dos respondentes não são licenciados em Ciências Sociais é alarmante.

Buscamos, por meio da Tabela 5, destacar a distribuição dos professores de Sociologia respondentes da presente pesquisa quanto ao tempo de formação como docente habilitado em Sociologia/Ciências Sociais.

Tabela 5 - Distribuição dos questionados habilitados em Sociologia por tempo de formação Tempo de formação Habilitados

\begin{tabular}{lr}
\hline Mais de 12 anos & $6,18 \%$ \\
Entre 9 e 12 anos & $9,27 \%$ \\
Entre 5 a 8 anos & $13,27 \%$ \\
Entre 4 e 2 anos & $18,91 \%$ \\
Menos de 2 anos & $6,00 \%$ \\
\hline
\end{tabular}
2013.

Fonte: Elaborada pelos autores com base nos questionários aplicados em

Quando analisamos o tempo de formação dos professores que lecionam Sociologia (ver Tabela 5), verificamos que o percentual de professores habilitados (licenciados em Ciências Sociais/Sociologia) é bem menor do que o de não habilitados. Essa diferença reduz-se entre os formados mais recentes, exceto entre aqueles que se formaram há menos de 2 anos. Temos duas hipóteses: i) a obrigatoriedade da Sociologia no Ensino Médio tem estimulado a procura pela licenciatura em Sociologia nos últimos anos; ii) os que se licenciaram há menos de 2 anos já podem estar tendo dificuldades de se inserir no mercado, já que, segundo o 
O PERFIL DO PROFESSOR BRASILEIRO DE SOCIOLOGIA DO ENSINO MÉDIO E SUA

PERCEPÇÃO DA CONDIÇÃO DOCENTE

Cristiano das Neves Bodart

Roniel Sampaio Silva

Censo da Educação Superior, em 2011, foram formados em Ciências Sociais/licenciatura 1.642 profissionais. Recordamos que Meucci (2000) identificou que antes da recente obrigatoriedade do ensino de Sociologia havia uma deficiência na formação de professores (habilitados) de Sociologia, tendo as universidades priorizado o bacharelado por falta de mercado de trabalho para o docente dessa disciplina, o que explicaria a baixa presença de licenciados em Sociologia/Ciências Sociais com tempo de formação superior a 12 anos.

A preocupação, destacada por Meucci (2000), de que as universidades não estavam formando professores de Sociologia (licenciados), mas apenas bacharéis, até os anos 1990, fica de certa forma evidenciada nesta pesquisa, porém, o cenário atual parece sofrer mudanças, ainda que tímidas. Não podemos afirmar, ao certo, o que ocorre atualmente, apenas levantar algumas hipóteses, as quais esta pesquisa não tem condições, por sua natureza e foco, de testar: i) os bacharéis em Sociologia não migraram para as salas de aula, como muitos previam; ii) as universidades estão priorizando a licenciatura, em detrimento do bacharelado, sem, contudo, conseguir atender a demanda por professores; iii) os licenciados em Ciências Sociais/Sociologia têm buscado outros mercados. O certo é que atualmente a disciplina de Sociologia não é ministrada apenas por professores licenciados em Ciências Sociais/Sociologia, o que é evidenciado por esta pesquisa, que explicita como percentual de licenciados em Sociologia/Ciências Sociais apenas 61,3\%. Há uma deficiência muito grande nesse aspecto, o que pode estar comprometendo significativamente a maior consolidação dessa disciplina no currículo escolar do Ensino Médio.

Para Enguita (1991, p. 41), é importante destacar que a profissionalização não é sinônimo de conhecimento, qualificação, formação e capacitação, mas a "expressão de uma posição social e ocupacional, da inserção em um tipo determinado de relações sociais de produção e de processo de trabalho". Contudo, o processo de formação continuada é um indicativo objetivo que pode corroborar a compreensão da qualificação do profissional. A formação docente, em especial, requer continuidade. Desse modo, buscamos analisar a formação complementar dos 
O PERFIL DO PROFESSOR BRASILEIRO DE SOCIOLOGIA DO ENSINO MÉDIO E SUA

PERCEPÇÃO DA CONDIÇÃO DOCENTE

Cristiano das Neves Bodart

Roniel Sampaio Silva

professores de Sociologia. A Tabela 6 apresenta a distribuição dos dados coletados a esse respeito.

Tabela 6 - Distribuição dos questionados por formação complementar

\begin{tabular}{|c|c|c|}
\hline Formação complementar & Frequência & $\%$ \\
\hline Não possuo formação complementar & 234 & 42,5 \\
\hline Especialização em outras Ciências Humanas & 118 & 21,5 \\
\hline $\begin{array}{l}\text { Especialização em Ciências Sociais ou } \\
\text { Sociologia }\end{array}$ & 72 & 13,1 \\
\hline Mestrado em Ciências Sociais ou Sociologia & 48 & 8,7 \\
\hline $\begin{array}{l}\text { Complementação ped. em Ciências Sociais ou } \\
\text { Sociologia }\end{array}$ & 34 & 6,2 \\
\hline Mestrado em outras Ciências Humanas & 30 & 5,5 \\
\hline Doutorado em Ciências Sociais ou Sociologia & 8 & 1,5 \\
\hline Especialização em Ciências Exatas & 4 & 0,7 \\
\hline Mestrado em Ciências Exatas/Naturais & 2 & 0,4 \\
\hline Total & 550 & $\overline{100}$ \\
\hline
\end{tabular}

Fonte: Elaborada pelos autores com base nos questionários aplicados em 2013.

A partir da Tabela 6, é possível perceber que a maioria (42,5\%) dos professores de Sociologia questionados que atuam no Ensino Básico não tem nenhuma formação complementar. Apenas 1,5\% possui doutorado em Ciências Sociais, 8,7\% têm mestrado em Ciências Sociais/Sociologia e 13,1\%, especialização em Ciências Sociais/Sociologia. Esses dados evidenciam, somados ao grande percentual de professores de Sociologia não formados na área, a deficiência na formação, sobretudo, na formação continuada dos que lecionam Sociologia no Ensino Médio. Em síntese, aferimos que, além da deficiência da profissionalização inicial, existem limitações no que concerne à formação continuada do professor de Sociologia.

Buscando observar a participação em eventos, identificamos que mais de 26\% dos professores que lecionam Sociologia não participam de nenhuma programação acadêmica, situação que demonstra as dificuldades de atualização de 
O PERFIL DO PROFESSOR BRASILEIRO DE SOCIOLOGIA DO ENSINO MÉDIO E SUA PERCEPÇÃO DA CONDIÇÃO DOCENTE

Cristiano das Neves Bodart

Roniel Sampaio Silva

mais de um quarto $(1 / 4)$ dos professores de Sociologia que participaram desta pesquisa. Destacamos que não há diferença substancial entre licenciados em Sociologia ou não licenciados em relação à (não) participação em eventos acadêmicos.

$\mathrm{Na}$ Tabela 7, apresentamos a distribuição dos respondentes por tempo de docência em Sociologia no Ensino Médio.

Tabela 7 - Distribuição dos questionados por tempo de docência em Sociologia no Ensino Médio.

\begin{tabular}{lr}
\hline $\begin{array}{l}\text { Tempo que leciona a disciplina de } \\
\text { Sociologia }\end{array}$ & $\%$ \\
\hline Menos de 1 ano & 25,3 \\
1 a 2 anos & 26,0 \\
3 a 5 anos & 29,8 \\
6 a 10 anos & 13,3 \\
Mais de 10 anos & 5,6 \\
\hline Total & $\mathbf{1 0 0}$
\end{tabular}

Fonte: Elaborada pelos autores com base nos questionários aplicados em 2013.

A Tabela 7 indica que os professores de Sociologia do Ensino Médio parecem formar uma categoria recentemente ampliada, fato provocado pelo histórico de quase ausência dessa disciplina no currículo básico brasileiro, realidade que somente foi alterada em 2008, após sua obrigatoriedade.

Ao analisarmos e compararmos o tempo de experiência dos professores e professoras (Gráfico 1), notamos que os educadores com mais tempo de docência são predominantemente do sexo feminino.

Gráfico 1 - Distribuição dos questionados por sexo e tempo formação. 
INTER-LEGERE

O PERFIL DO PROFESSOR BRASILEIRO DE SOCIOLOGIA DO ENSINO MÉDIO E SUA

PERCEPÇÃO DA CONDIÇÃO DOCENTE

Cristiano das Neves Bodart

Roniel Sampaio Silva

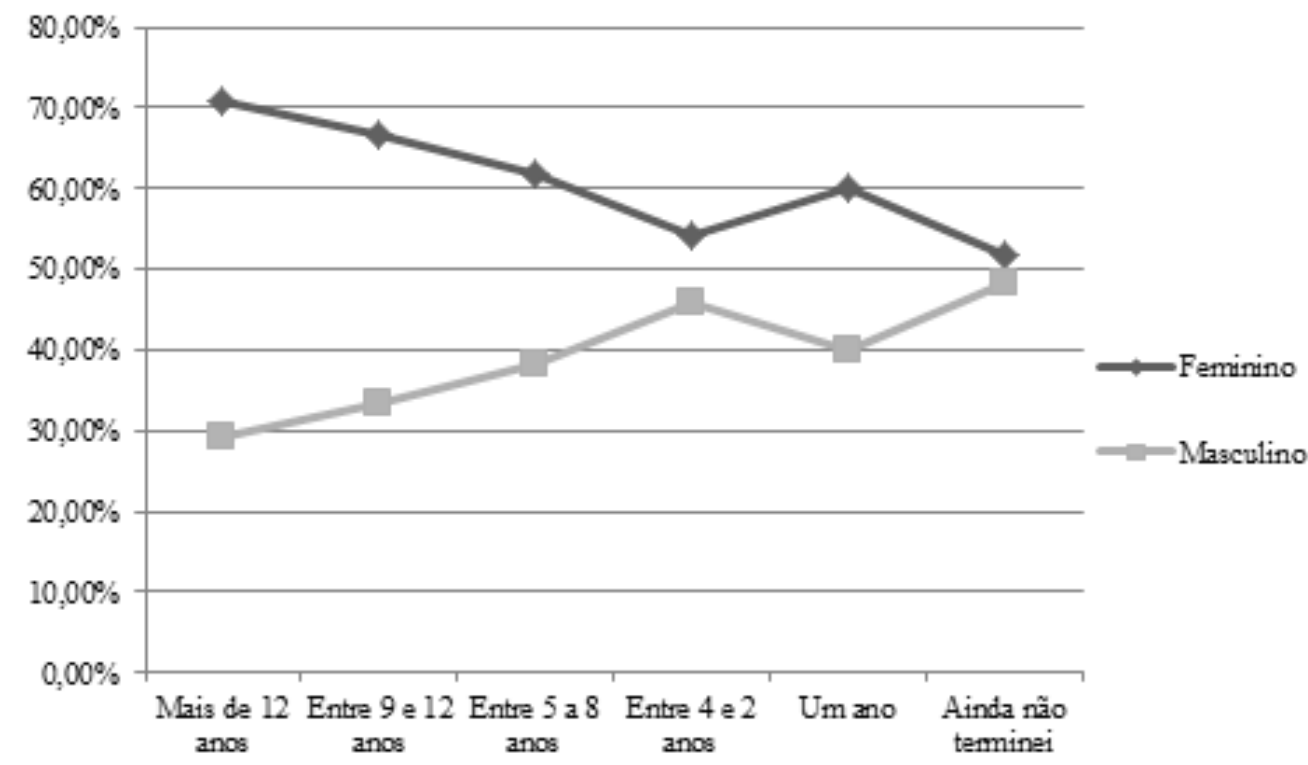

Fonte: Elaborado pelos autores com base nos questionários aplicados em 2013.

Os dados do Gráfico 1 indicam uma tendência de mudança na composição do professor de Sociologia em relação à variável sexo, apontando uma convergência de equilíbrio. Ao realizarmos a mesma análise tomando apenas os professores licenciados, percebemos que a predominância de professoras observadas na análise anterior (Gráfico 1) continua sendo destacada entre os licenciados em Ciências Sociais/Sociologia. Da mesma forma, identificamos uma probabilidade de redução na disparidade de composição por sexo entre professores licenciados em Sociologia, porém, ligeiramente menor, quando comparada com a disparidade existente entre os professores em geral que lecionam Sociologia.

A partir da análise realizada nesta seção em relação ao perfil dos 550 professores que responderam o questionário, é notório que há uma predominância de professores do sexo feminino, indicando uma tendência recente de maior equilíbrio. A categoria de professores de Sociologia é bastante nova, constituída em sua grande parte por não licenciados na área. Além disso, poucos professores que lecionam Sociologia se qualificaram para além da graduação, dificuldade ainda maior quando a formação complementar é em Ciências Sociais/Sociologia, caracterizando apenas $29,5 \%$ dos profissionais. 


\section{CONDIÇÕES DO TRABALHO DOCENTE: O ENSINAR SOCIOLOGIA}

Lennert (2011), ao buscar discutir a situação do trabalho docente do professor de Sociologia, afirmou que é necessário consolidar a inclusão da disciplina no Ensino Básico, sobretudo, oferecendo condições de trabalho adequadas e proporcionando condições materiais melhores.

Identificados alguns elementos que compõem o perfil do professor que leciona Sociologia no Ensino Básico, resta-nos agora procurar compreender as suas condições de trabalho. Uma das queixas mais corriqueiras entre os professores é o excesso de aulas semanais. Lennert (2011) apontou a necessidade de uma jornada de trabalho semanal não elevada para que o professor de Sociologia possa ter tempo para planejar bem suas aulas. Em seu estudo, essa mesma autora identificou que em São Paulo o professor de Sociologia possuía uma carga horária de trabalho excessiva. No caso da Sociologia, esse tempo de planejamento pode ser muito importante pela carência de indicações de conteúdos mínimos, material pedagógico e métodos de ensino consolidados. Com vista a identificar se o professor de Sociologia vivencia essas dificuldades, constatamos por meio da presente pesquisa que $52 \%$ dos professores lecionam mais de 20 aulas por semana, confirmando a queixa do tamanho da jornada de trabalho (ver Tabela 8). Um percentual superior a $32 \%$ dos professores que lecionam Sociologia têm mais de 25 aulas semanais, o que certamente dificulta suas práticas docentes e a formação continuada, como também a elaboração de planos de aulas e leituras básicas para manterem-se informados e aprofundarem seus conhecimentos.

Tabela 8 - Distribuição dos questionados por quantidade de aulas lecionadas por semana.

\begin{tabular}{lrr}
\hline Quantidades semanais de aulas & Frequência & $\%$ \\
\hline 4 ou menos & 61 & 11,1 \\
Entre 5 e 8 & 74 & 13,5 \\
Entre 9 e 12 & 67 & 12,2 \\
Entre 13 e 16 & 55 & 10
\end{tabular}


INTER-LEGERE

O PERFIL DO PROFESSOR BRASILEIRO DE SOCIOLOGIA DO ENSINO MÉDIO E SUA

PERCEPÇÃO DA CONDIÇÃO DOCENTE

Cristiano das Neves Bodart

Roniel Sampaio Silva

Entre 17 e 20

61

21 a 24

11,1

25 a 28

56

9,5

29 a 32

61

10,2

33 ou mais

63

11,1

Total

550

11,5

Fonte: Elaborada pelos autores com base nos questionários aplicados em 2013.

O grande número de aulas a serem lecionadas semanalmente dificulta o seu planejamento, muitas vezes, levando o docente a apoiar-se quase que por completo no livro didático.

Reconhecendo a importância sesse instrumento didático, buscamos identificar se os alunos têm tido acesso a essa ferramenta pedagógica. Scheffer (2011), ao entrevistar professores de Sociologia do Ensino Médio da cidade de Juiz de ForaMG, observou que a reclamação por falta de livros didáticos é bastante generalizada, embora seja o material mais utilizado por eles como apoio para a seleção de conteúdos. Procuramos, também, nesta pesquisa, notar se esse é um problema que afeta os professores que lecionam Sociologia. Dentre os docentes que participaram desta pesquisa, $37,5 \%$ deles afirmam que os seus alunos não têm acesso ao livro didático de Sociologia, o que nos parece bastante problemático. No ano de 2015, o MEC ampliou o atendimento a essa necessidade, disponibilizando uma variedade maior de obras a serem adotadas pelo professor, bem como a ampliação do número de escolas públicas atendidas.

Frente à dificuldade de trabalhar com o livro didático, buscamos identificar se outras ferramentas pedagógicas são utilizadas para suprir essa deficiência. $\mathrm{Na}$ ausência de livro didático, a biblioteca da escola pode ser auxílio ao professor e ao educando. A Tabela 9 apresenta a percepção do professor em relação às condições bibliográficas da biblioteca da escola onde atua.

Tabela 9 - Percepção do professor em relação às condições bibliográficas da biblioteca da escola onde atua. 


\begin{tabular}{lrr}
\hline & & Frequência \\
& & \% \\
\hline A biblioteca atende plenamente à necessidade da disciplina & 57 & 10,4 \\
A biblioteca não possui livros de Sociologia & 78 & 14,2 \\
A biblioteca possui poucos livros de Sociologia & 382 & 69,5 \\
Não há biblioteca na instituição & 33 & 6,0 \\
\hline Total & $\mathbf{5 5 0}$ & $\mathbf{1 0 0 , 0}$
\end{tabular}

Fonte: Elaborada pelos autores com base nos questionários aplicados em 2013.

Por meio da Tabela 9, percebemos que os professores, em sua maioria $(89,6 \%)$, não contam com um apoio satisfatório da biblioteca. A falta de livros de Sociologia nas bibliotecas das escolas, somada à dificuldade de acesso ao livro didático, certamente compromete a qualidade do trabalho docente.

Concordamos com Nóvoa (1995, p. 16-17), quando afirma que "cada um tem o seu modo próprio de organizar as aulas, de se movimentar na sala, de se dirigir aos alunos, de utilizar os meios pedagógicos, um modo que constituiu uma espécie seguida pelo profissional". Embora exista uma prática docente própria de cada professor, algumas ferramentas são considerados fundamentais, especialmente quando se busca um ensino estimulante. Diante disso, selecionamos três instrumentos ${ }^{11}$ para averiguarmos a sua utilização pelo professor de Sociologia: livro didático; laboratório de informática; e músicas.

Observamos, então, se outros recursos têm sido utilizados. A Tabela 10 aponta a situação referente ao uso do laboratório de informática nas aulas de Sociologia.

Tabela 10 - Uso do laboratório de informática nas aulas de Sociologia.

\begin{tabular}{lcc}
\hline $\begin{array}{l}\text { Uso do laboratório de informática nas aulas de } \\
\text { Sociologia }\end{array}$ & Frequência \\
\hline Frequentemente & 66 & 12 \\
& \\
& $\begin{array}{l}11 \text { Reconhecemos que o uso do instrumento, por si só, não garante aulas mais atrativas, mas a sua } \\
\text { não utilização dificulta ainda mais uma prática docente que busca ser atraente. }\end{array}$
\end{tabular}


INTER-LEGERE

O PERFIL DO PROFESSOR BRASILEIRO DE SOCIOLOGIA DO ENSINO MÉDIO E SUA

PERCEPÇÃO DA CONDIÇÃO DOCENTE

Cristiano das Neves Bodart

Roniel Sampaio Silva

\begin{tabular}{lrr} 
Não utilizo por não existir na instituição & 33 & 6 \\
Não utilizo, embora exista na instituição & 209 & 38 \\
Utilizo poucas vezes & 242 & 44 \\
\hline Total & $\mathbf{5 5 0}$ & $\mathbf{1 0 0}$
\end{tabular}

Fonte: Elaborada pelos autores com base nos questionários aplicados em 2013.

Por meio da tabela 10 , contabilizamos que apenas $12 \%$ dos professores de Sociologia usam com frequência o laboratório de informática em suas aulas de Sociologia. Identificamos, além disso, que o número de professores que não o utilizam é bastante elevado (44\%). Buscamos, ainda, averiguar outro recurso: o uso de músicas nas aulas de Sociologia ${ }^{12}$.

Tabela 11 - Uso de músicas nas aulas de Sociologia.

\begin{tabular}{lrr}
\hline Uso de músicas nas aulas de Sociologia & Frequência & $\%$ \\
\hline Não utilizo & 112 & 20,4 \\
Raramente utilizo & 100 & 18,2 \\
Utilizo frequentemente (mais de uma vez por semestre em cada turma) & 187 & 34 \\
Utilizo pouco (cerca de uma vez por semestre em cada turma) & 151 & 27,5 \\
\hline Total & $\mathbf{5 5 0}$ & $\mathbf{1 0 0}$
\end{tabular}

Fonte: Elaborada pelos autores com base nos questionários aplicados em 2013.

Dentre os recursos observados na pesquisa, a música apareceu como o mais utilizado nas aulas de Sociologia. Possivelmente, o uso de músicas nessa disciplina se deve pela facilidade de acesso ao material e por ser algo que faz parte do cotidiano dos educandos, quase que independentemente de sua condição social.

É consenso que a atuação do docente em mais de uma instituição de ensino é bastante prejudicial à sua prática. Lennert (2011), ao discutir a questão do tempo gasto na prática docente, deixa claro que, com o planejamento das aulas sendo afetado, o professor não disporá de condições adequadas para desenvolver aulas

\footnotetext{
${ }^{12}$ A respeito do uso de músicas como recurso didático em aulas de Sociologia, indicamos o artigo de Cristiano das Neves Bodart, intitulado "O uso de letras de músicas nas aulas de Sociologia", publicado na Revista Café com Sociologia, v. 1, n. 1, 2012. Disponível em: <http://revistacafecomsociologia.com/revista/index.php/revista/article/view/1 >. Acesso em: nov. 2015.
} 
O PERFIL DO PROFESSOR BRASILEIRO DE SOCIOLOGIA DO ENSINO MÉDIO E SUA

PERCEPÇÃO DA CONDIÇÃO DOCENTE

Cristiano das Neves Bodart

Roniel Sampaio Silva

atrativas. A transição do professor de uma escola para outra, seja lecionando em duas, seja em mais escolas no mesmo ano, ou para uma nova escola a cada ano, pode impossibilitar que a sua identidade seja reconhecida pelos demais (LENNERT, 2011, p. 368).

Tabela 12 - Número de escolas em que o professor de Sociologia leciona.

\begin{tabular}{|c|c|c|}
\hline Quantidade de instituições & Frequência & $\%$ \\
\hline 1 & 294 & $53,45 \%$ \\
\hline 2 & 171 & $31,09 \%$ \\
\hline 3 & 59 & $10,73 \%$ \\
\hline 4 & 17 & $3,09 \%$ \\
\hline 5 & 3 & $0,55 \%$ \\
\hline Mais de 5 & 6 & $1,09 \%$ \\
\hline
\end{tabular}

Fonte: Elaborada pelos autores com base nos questionários aplicados em 2013.

A Tabela 12 indica que $46,55 \%$ dos professores trabalham em duas ou mais escolas, percentual considerável e preocupante. Tendo que revezar entre duas ou mais escolas, seu desempenho pode ficar prejudicado por vários fatores, tais como a diferença entre a cultura organizacional da escola, a perda de tempo em deslocamento e o maior número de planos de aula diversificados de acordo com realidades diferentes dos educandos.

Conforme Oliveira (2004), vários fatores, tais como os papéis sociais que muitas vezes é forçado a assumir para além daquele de professor, têm levado o educador a um sentimento de desprofissionalização, de perda de identidade, de percepção de que ensinar às vezes não é o mais importante. No caso do professor que leciona Sociologia, essa constatação pode ser ainda mais comum, frente à subvalorização de sua disciplina no currículo escolar.

Tabelas 13 e 14 - Percepção do professor que leciona Sociologia sobre o valor que os demais professores e alunos dão à disciplina. 
INTER-LEGERE

O PERFIL DO PROFESSOR BRASILEIRO DE SOCIOLOGIA DO ENSINO MÉDIO E SUA

PERCEPÇÃO DA CONDIÇÃO DOCENTE

Cristiano das Neves Bodart

Roniel Sampaio Silva

\section{Percepção sobre a importância}

que os professores dão à

disciplina

Disciplina importante

Disciplina menos importante do que as demais

Disciplina não importante

Total
Percepção sobre a importância que os alunos dão à disciplina

22,9 Disciplina importante

21,5

64,7 Disciplina menos importante que as demais

55,1

12,4 Disciplina não importante

23,5

100

Fonte: Elaboradas pelos autores com base nos questionários aplicados em 2013.

Em face dos diversos problemas identificados na presente pesquisa, objetivamos averiguar a percepção do professor de Sociologia quanto ao valor que os demais professores e alunos dão à disciplina. Sousa e Ribeiro (2012), ao estudarem as condições de trabalho dos professores de Sociologia em Picos-PI, apontaram como uma das principais reclamações o não reconhecimento da importância da disciplina pelos demais colegas de trabalho, que lecionam outras disciplinas. Nesta pesquisa, de nível nacional, a situação não é diferente. As Tabelas 13 e 14 apresentam duas situações preocupantes: i) 77,1\% dos professores de Sociologia percebem que os docentes de outras disciplinas consideram a Sociologia como menos importante em relação às demais ou não importante; ii) $78,6 \%$ dos professores de Sociologia percebem que os alunos não a consideram importante. Certamente, a percepção do educador da (não)valorização de sua disciplina desmotiva a prática docente e acaba afetando diretamente a sua autoestima. No caso do professor que leciona Sociologia, além das diversas dificuldades já apresentadas, ter que lidar com problemas de cunho emocional certamente é um grande desafio.

\section{CONSIDERAÇÕES FINAIS}

Conforme apresentado, há muitos desafios no que tange ao ensino de Sociologia no Brasil. O principal deles está na deficiência na formação de licenciados em Ciências Sociais e na formação continuada. O número de professores de Sociologia licenciados em Ciências Sociais/Sociologia tem 
O PERFIL DO PROFESSOR BRASILEIRO DE SOCIOLOGIA DO ENSINO MÉDIO E SUA

PERCEPÇÃO DA CONDIÇÃO DOCENTE

Cristiano das Neves Bodart

Roniel Sampaio Silva

aumentado nos últimos anos, entretanto, sua participação na composição dos professores que atuam nessa disciplina ainda está longe do desejável.

Os docentes de Sociologia apresentam significativa deficiência em relação à formação complementar. Pelo fato de terem ingressado recentemente na docência, ainda precisam desenvolver muito dos saberes experienciais (TARDIF, 2002) para consolidarem suas práticas e utilizarem estratégias didáticas diversificadas.

Identificamos que a composição do docente brasileiro de Sociologia tem se modificado quanto ao sexo. Os docentes do sexo masculino gradativamente têm ampliado sua participação, que outrora predominantemente era feminina.

Além dos problemas da precariedade das escolas públicas, tão difundidos pela mídia, percebemos que a disciplina de Sociologia ainda precisa ser mais valorizada pelos sistemas de ensino, uma vez que esta pesquisa aponta que a maioria dos docentes ainda não possui, em grande parte, acesso ao livro didático e a livros de apoio para trabalhar com os alunos. Há um número considerável de professores que atuam em mais de uma instituição, sendo um indício de que esses docentes têm muitas turmas (já que a carga horária da disciplina é geralmente de uma ou duas horas semanais por turma), o que fragmenta e precariza a atividade docente.

Como consequência de todos esses problemas apresentados, a disciplina ainda não é significativamente reconhecida pelos alunos e demais professores. As condições e oportunidades dadas aos docentes de Sociologia ainda estão muito aquém do necessário para uma prática docente "decente", capaz de criar discentes e não "dissidentes".

\section{REFERÊNCIAS}

BRASIL. Governo Provisório da República dos Estados Unidos do Brasil. Decreto no 19.890, de 18 de abril de 1931. Disponível em:

<http://www2.camara.gov.br/legin/fed/decret/1930-1939/decreto-19890-18-abril1931-504631-publicacaooriginal-83133-pe.html>. Acesso em: 16 jan. 2016

ENGUITA, Mariano F. A ambiguidade da docência: entre o profissionalismo e a 
O PERFIL DO PROFESSOR BRASILEIRO DE SOCIOLOGIA DO ENSINO MÉDIO E SUA PERCEPÇÃO DA CONDIÇÃO DOCENTE

Cristiano das Neves Bodart

Roniel Sampaio Silva

proletarização. Revista Teoria \& Educação, n. 4, pp.25-37, 1991.

INEP/MEC. Censo Escolar 2009. Brasília: Inep, 2012.

INEP/MEC. Censo Escolar 2012. Brasília: Inep, 2012.

INEP/MEC. Estudo exploratório sobre o professor brasileiro: com base nos resultados do Censo Escolar da Educação Básica 2007 a 2011. Brasília: Inep, 2012.

LENNERT, Ana Lúcia. Condições de trabalho do professor de Sociologia. Cad. Cedes, Campinas, v. 31, n. 85, p. 383-403, set.-dez. 2011.

MEUCCI, Simone. A institucionalização da Sociologia no Brasil: Os primeiros manuais e cursos. 2000. Dissertação (Mestrado em Sociologia) - IFCH, UNICAMP, Campinas, 2000.

MORAES, Amaury. Ensino de sociologia: periodização e campanha pela obrigatoriedade. Cad. Cedes, Campinas, v. 31, n. 85, p. 359-382, set.-dez. 2011.

NASCIMENTO, Alessandra Santos. Fernando de Azevedo: institucionalização da sociologia e modernização brasileira. Perspectivas: Revista de Ciências Sociais, 2010.

NÓVOA, Antônio. Vida de professores. 2. ed. Porto: Porto, 1995. (Coleção Ciência da Educação).

OLIVEIRA, Dalila Andrade. A reestruturação do trabalho docente: precarização e flexibilização. Educ. Soc., Campinas, v. 25, n. 89, p. 1127-1144, set.-dez. 2004.

SANTOS, Mário Bispo. A Sociologia no Ensino Médio: o que pensam os professores da Rede Pública do Distrito Federal. 2002. Dissertação (Mestrado em Sociologia) - Universidade de Brasília, Brasília, 2002.

SCHEFFER, Thaís Sartori. A seleção de conteúdos de sociologia por professores do ensino médio. 2011. Monografia (Curso de Graduação em Ciências Sociais) - UFJF, 2011.

SOUSA, Maria das Dôres; RIBEIRO, Márcia Maria Gurgel. Docência e identidade profissional do professor de Sociologia do Ensino Médio. Revista Inter-legere, v. 11, pp. 68-89, jul.-dez. 2012.

TARDIF, Maurice. Saberes docentes e formação profissional. Petrópolis: Vozes, 2002. 